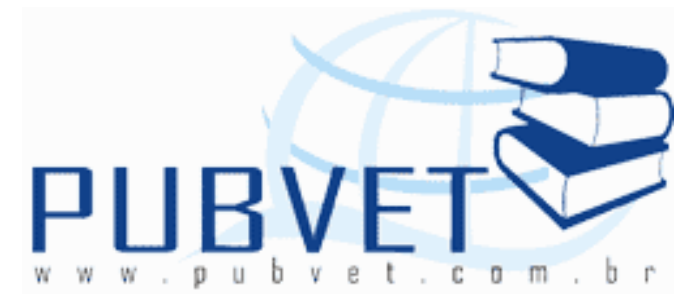

PUBVET, Publicações em Medicina Veterinária e Zootecnia.

\title{
Atresia anal associada à fístula reto-vaginal em bezerra: uma revisão
}

Yndyra Nayan Teixeira Carvalho ${ }^{1}{ }^{*}$, Marlon de Araújo Castelo Branco ${ }^{1}$; Luiz Harliton Cavalcante Monteiro Mota ${ }^{1}$, Luanna Soares de Melo Evangelista ${ }^{1}$, Severino Vicente da Silva², Francisco Solano Feitosa Júnior ${ }^{2}$

(1) Pós-graduandos em Ciência Animal - Universidade Federal do Piauí - UFPI; *autor para correspondência: Yndyranayan1@hotmal.com

(2) Professor Doutor do Departamento de Clínica e Cirurgia Veterinária da Universidade Federal do Piauí - UFPI

\section{Resumo}

A atresia anal é uma deformidade que acomete a abertura anal e reto terminal, resultando em fechamento da saída anal e/ou da via anormal das fezes por meio da vagina ou da uretra. Quatro tipos de atresia anal são descritos, incluindo estenose anal (tipo I), ânus imperfurado (tipo II) ou combinado com porção terminal do reto cranial a membrana anal (tipo III) e o tipo IV que ocorre em fêmeas, onde há uma comunicação persistente entre o reto e a vagina ou entre o reto e a uretra. Esta revisão tem como objetivo descrever sobre essa enfermidade que é uma malformação de ocorrência muito rara, classificada como uma anomalia anorretal alta, abordando suas características gerais em bezerras.

Palavras-chave: Bezerro, fezes, atresia. 


\title{
Anal atresia associated with recto-vaginal fistula in calf: A review
}

\begin{abstract}
The anal atresia deformity is affecting the rectum and anal opening the terminal, resulting in closing the outlet anal and/or abnormal pathway faeces through the vagina or the urethra. Four types of anal atresia are described, including stenosis anal (type I), anus (type II) or combined with the terminal portion of the right cranial anal membrane (type III) and type IV which occurs in females, where there is a continuing communication between the rectum and vagina or between the rectum and urethra. This review aims to describe about this disease is a very rare occurrence of malformation, classified as a high anorectal anomaly, discussing its general characteristics in calves.
\end{abstract}

Keywords: Calf, stools, Atresia.

\section{INTRODUÇÃO}

As malformações ou defeitos congênitos são anormalidades estruturais ou funcionais presentes ao nascimento, que acometem os sistemas de forma parcial ou totalmente, nas fases de desenvolvimento embrionário ou fetal de todas as espécies de animais (ROTTA et al., 2008).

As malformações apresentam distribuição mundial e podem causar danos reprodutivos, como aborto, malformações, retardo de crescimento intrauterino e deficiências funcionais (PIMENTEL et al., 2007). Em bovinos, as anomalias congênitas são de ocorrência pouco freqüente, tendo incidência estimada de 0,2 a 5\%. Acredita-se que essas anomalias sejam induzidas por fatores genéticos ou ambientais (LOYNACHAN et al., 2006).

Entre os principais fatores ambientais ou fatores de risco envolvidos, incluem-se os nutricionais, a presença de teratógenos como a radiação, o uso da cortisona, a ocorrência de doenças maternas, traumatismos, a utilização de drogas como os benzimidazóis e a ingestão de plantas tóxicas, e os fatores 
físicos do útero relacionados às quantidades anormais de líquido amniótico (GERALDO NETO et al., 2001; FELIPE, 2003;PUGH, 2004).

Segundo Felipe (2003), os defeitos congênitos seriam a causa de até $15 \%$ de óbito nas primeiras 48 horas de vida. No Brasil, já foram mencionados em búfalos (SCHILD et al., 2003), caprinos (SCHMIDT e OLIVEIRA, 2004; PIMENTEL et al., 2007), ovinos (NÓBREGA et al., 2005) e bovinos (SANTOS et al., 2005).

No semiárido do Nordeste Brasileiro são observadas com freqüência vários tipos de malformações congênitas, incluindo anomalias ósseas craniofaciais, malformações oculares e artrogripose em ovinos, caprinos (MEDEIROS et. al. 2005) e bovinos (Riet-Correa et al.,2006) criados extensivamente.

Campo (2009) ao realizar um estudo retrospectivo das enfermidades congênitas em bezerros, diagnosticadas pela CEDIVET no período de 1999 a 2009, provenientes de diferentes propriedades localizadas no estado do Pará, observou que dentre os 39 animais diagnosticados com alterações congênitas, a prevalência de alterações do sistema urogenital foi de $20,51 \%$, incluindo $2,5 \%$ referente à atresia anal.

Diante do exposto, objetivou-se com esse trabalho descrever sobre a atresia anal, considerada uma malformação congênita, de ocorrência rara, mas que pode comprometer a reprodução e a produtividade do animal, abordando as características gerais dessa enfermidade em bezerras.

\section{ANATOMIA DA REGIÃo PERINEAL E ÂNUS}

A região do períneo se divide mediante uma linha que une ambas as tuberosidades isquiáticas, em uma parte dorsal (região anal) e outra ventral (região urogenital). A região do períneo possui os seguintes limites: - dorsal, a raiz da cauda; - lateral, o ligamento sacrotuberal e os processos dorsais, ventro-medial da tuberosidade isquiática e uma linha sagital da tuberosidade isquiática até o limite ventral; - ventral, uma linha que vai desde a 
tuberosidade isquiática até o limite caudal da mama ou do escroto (BERG, 1978).

De acordo com Schwarze (1971), a porção final do intestino grosso é o reto, que está situado ventralmente ao sacro e as primeiras vértebras caudais percorrendo em direção reta até o ânus. O intestino grosso estende-se da terminação do íleo ao ânus e é dividido em cecum, cólon e reto (SISSON e GROSSMAN'S, 1986).

O termo reto significa um trajeto reto, mais frequentemente esta parte do intestino é desviada para um lado por pressão de outras vísceras, mais comumente uma vesícula urinária distendida (DYCE, 1990). O reto é muito dilatado e seu tamanho varia conforme a espécie animal, sendo nos bovinos de 30 a $40 \mathrm{~cm}$ (SCHWARZE, 1971).

$O$ reto consiste em uma parte cranial em grande parte coberta por peritônio e uma parte retroperitoneal mais larga, a ampola do reto (SISSON e GROSSMAN'S, 1986).

O canal anal que liga o intestino com o exterior é caracterizado por ser uma passagem curta originário do proctodeu, a invaginação do ectoderma superficial. A luz é estreita na junção retoanal, onde a mucosa é moldada em pregas longitudinais, normalmente comprimidas em conjunto para ocluir o orifício (DYCE, 1990).

O canal anal, juntamente com o ânus, forma o final do tubo intestinal, atuando, com o auxílio do músculo esfíncter anal interno de musculatura lisa e do músculo esfíncter anal externo de musculatura estriada, na oclusão do segmento terminal do intestino. Na região do ânus, a mucosa glandular do canal anal apresenta uma mucosa estriada, limitando-se com a pele externa (KONIG, 2002).

O canal anal é suprido pelos ramos terminais da artéria média e cranial do reto e pela artéria caudal do reto na bifurcação terminal do ramo caudal da artéria urogenital. Nervos simpáticos do plexo mesentérico caudal atingem o reto através do plexo retal cranial. Entretanto, o principal suprimento parassimpático do reto e a inervação do ânus e do esfíncter externo do ânus 
vêm dos nervos caudais do reto. O ramo perineal profundo do nervo pudendo também fornece um ramo para o esfíncter externo do ânus (SISSON e GROSSMAN'S, 1986).

Em uma revisão feita por Barbosa (1983) sobre o sistema linfático dos bovinos, informou que o linfonodo anal localizado sobre o teto da pélvis lateralmente ao ânus, drena a região anal via vasos aferentes, levando a linfa aos linfonodos sub-sacrais, por sua vez, localizados, sob o sacro, no ângulo formado pelas duas artérias ilíacas internas. Estes linfonodos recebem a linfa oriunda da região anal e a levam ao último linfonodo da cadeia lombo-aórtica. Tais linfonodos, localizados sob a região lombar ao longo dos troncos vasculares sub-lombares, recebem, via vasos aferentes, a linfa de toda a região muscular lombar, assim como dos linfonodos íleo-pelvianos e levam esta linfa, via vasos eferente, a Cisterna de Pecquet. A linfa produzida na região glútea e na região femural do membros posteriores, assim como a oriunda dos linfonodos poplíteos, é drenada aos linfonodos isquiáticos que estão localizados a altura do músculo ísqueo-anal, sobre a face externa do ligamento sacro espino-tuberal e sobre o trajeto da artéria isquiática. Destes linfonodos, a linfa é levada aos linfonodos sub-sacrais via vasos eferentes.

\section{HISTOLOGIA DA REGIÃo PERINEAL E ÂNUS}

A mucosa do reto, como a do cólon e a do ceco, é lisa e, exceto pelo maior número de células caliciformes, as estruturas básicas também são semelhantes. A camada muscular externa contém mais tecido elástico que a camada interna. A parte retroperitoneal do reto não possui uma túnica serosa ano-cutânea (DELLMANN, 1982; BROWN, 1982).

Próximo a sua junção com o ânus, a mucosa retal nos ruminantes formam pregas longitudinais, as colunas retais, entre as quais há depressões, os seios retais. Todos os animais domésticos possuem um plexo venoso relativamente bem desenvolvido na lâmina própria desta região do reto anocutânea (DELLMANN, 1982; BROWN, 1982). 


\section{ENFERMIDADE DA REGIÃo PERINEAL E ÂNUS}

Entre os processos patológicos do aparelho digestório, Santos (1975), citou a agenesia, a hipoplasia, a atresia anal simples, a atresia retal simples e a atresia ano-retal. Segundo Nieberle e Cohrs (1970), estas alterações acometem os suínos e bovinos, e raramente as outras espécies. Quando congênitas freqüentemente estão associadas com outros processos, principalmente no sistema gênito-urinário. A agenesia observou-se no ceco de bezerros e no colón de cães. A hipoplasia, aparentemente, pode ser freqüente. $\mathrm{Na}$ atresia anal simples, falta o orifício anal, enquanto a fossa anal está habitualmente presente, o esfíncter está desenvolvido e o reto completamente formado. Na aplasia retal simples o reto não se formou. Na atresia ano-retal o ânus e o reto estão obliterados e falta a fossa anal. Quando ocorrem fístulas comunicantes, haverá persistência de membrana anal associada com persistência do conduto cloacal. Desta forma, o reto comunica-se com os seios urogenitais.

Nas vacas, uma pressão no eixo longitudinal do feto em desenvolvimento, durante o exame retal de prenhez, entre os dias 37 e 41, pode causar a atresia do cólon. No entanto, na raça holstein parece também haver um padrão genético, possivelmente um gene autossômico recessivo, responsável por este defeito. Os bezerros com atresia do cólon eliminam pouco ou nenhum mecônio e desenvolvem cólicas logo após o nascimento (SIEGMUN, 1981).

A fístula retovaginal é um trato fistuloso que liga a vagina ao reto; geralmente ocorre em conjunção com o ânus imperfurado. A passagem das fezes através da vulva ou sinais de obstrução colônica sugere sua ocorrência. O diagnóstico pode ser confirmado por enema de bário, que define a extensão do defeito no interior da vagina. A identificação da fístula, sua correção cirúrgica e o restabelecimento das estruturas anatômicas normais são imperativos. O prognóstico geralmente é reservado. Freqüentemente são 
vistas complicações, tais como incontinências fecais e urinárias (SIEGMUN, 1981).

\section{ATRESIA ANAL ASSOCIADA A FÍSTULA RETO-VAGINAL EM BEZERRAS}

As anomalias anorretais (AAR) é a denominação genérica que se dá a um conjunto de malformações congênitas (Tudury e Lorenzoni, 1989) do canal anal, retal ou de ambos. O termo imperfuração anal, nome pelo qual também são conhecidas, se deve ao fato de que tais malformações resultam em ausência de correta abertura do ânus.

As anomalias anorretais constituem um amplo espectro de doenças que variam desde defeitos de pequena monta, de fácil tratamento, até outros de extrema complexidade e de difícil resolução no que concerne ao controle intestinal, urinário e função sexual (PENÃ, 1992).

As anomalias anorretais são classificadas em altas, intermediárias e baixas de acordo com a posição do fundo de saco retal em relação ao músculo puborretal. Nesse complexo de malformações situa-se a atresia retal, de ocorrência muito rara, que é classificada como uma anomalia anorretal alta (DE VREIS, 1985; CAPELLA, 1990).

A atresia do ânus já foi descrita em suínos, ovinos e bezerros ( $\mathrm{CHO}$ e TAYLOR, 1986). Radostits et al. (2002), afirmaram que sua ocorrência é esporádica e nenhum fator genético ou de manejo pode ser indicado como causa. Em outras circunstâncias, a ocorrência pode ser sugestiva de herança, ou ser de tal freqüência que sugira alguma causa ambiente.

A atresia anal é uma deformidade que acomete a abertura anal e reto terminal, resultando em fechamento da saída anal e/ou da via anormal das fezes por meio da vagina ou da uretra (VIANNA, 2005).

Raramente essa afecção afeta os bovinos leiteiros. Os bovinos afetados mostram os sinais logo após o nascimento, pois ficam incapazes de eliminar o estrume (REBHUN, 2000). 
Animais que apresentam atresia anal ou estenose anal congênita revelam, por vezes, presença de fístula reto-vaginal ou reto-uretral associada (MATTHIESEN e MARRETTA, 1998; RAHAL e MORTARI, 2007), podendo apresentar também outras deformidades associadas (RAHAL e MORTARI, 2007).

Durante a vida embrionária o reto e a vagina terminam numa cloaca em comum. Porém, posteriormente, o reto migrará caudalmente separando-se da vagina. Se isto não ocorrer corretamente poderá surgir uma fístula retovaginal congênita (PRATT, 1983 apud TUDURY E LORENZONI, 1989). Nas fêmeas, a atresia anal pode vir acompanhada de fístula reto-vaginal, observando-se então a saída de fezes pela vulva (SLATTER, 1985). Como as parturientes limpam constantemente os filhotes, esta saída anormal de fezes muitas vezes só é constatada após o desmame (ARCHIBALD, 1974; SLATTER, 1985), momento no qual a dilatação do cólon já e muito grande (TUDURY e LORENZONI, 1989). O atraso na verificação das anormalidades deve-se também ao fato, de que a impactação do colón só começará a partir do momento em que os filhotes iniciam uma alimentação mais sólida (BOJRAB, 1981 apud TUDURY e LORENZONI, 1989).

A atresia anal pode ser classificada em quatro tipos, com base nos vários graus de disgenesia ou agenesia do reto e do ânus. A atresia anal do tipo 1 é caracterizada por um reto normal e um ânus estenótico. A atresia anal tipo 2 ou ânus imperfurado é descrita como um reto distal que termina em fundo cego sem desenvolvimento do ânus; frequentemente o reto é apropriadamente desenvolvido, porém o ânus é coberto por uma fina membrana de pele. A atresia anal tipo 3 caracteriza-se pela formação de um fundo cego no reto proximal e a ausência de ânus desenvolvido, enquanto a atresia anal tipo 4 é definida pela formação de fundo cego no reto proximal com o ânus desenvolvido normalmente (ARONSON, 2002; VIANNA, 2005).

A dificuldade diagnóstica se dá pelo aspecto normal do ânus (DE VREIS, 1985; COX, 1985; MORAES, 1986). A anamnese revelará ausência de eliminação de mecônio. 
O procedimento cirúrgico a ser realizado é denominado anoplastia, que pode ser parcial ou completa. Esta pode apresentar como complicações póscirúrgicas incontinência fecal, formação de constrição e deiscência dos pontos (MATTHIESEN e MARRETTA, 1998).

\section{ETIOLOGIA}

A atresia anal associado à fístula reto-vaginal é um defeito congênito que alguns autores sugerem ser de caráter hereditário. A atresia anal caracteriza-se por uma interrupção do reto próxima à junção muco-cutânea, cuja etiologia mais provável é uma catástrofe vascular (KIESEWETTER, 1979; MORAES, 1986). Diante da imperfuração da cavidade natural, a pressão exercida pelas contrações peristálticas em seu trânsito normal, força a abertura de um canal fistuloso, que em fêmeas, corre desde o reto até a vagina.

\section{EPIDEMIOLOGIA}

A atresia anal, um defeito congênito comum em animais, freqüentemente acomete bezerros e leitões. Sua ocorrência está relacionada à falha na perfuração da membrana que separa o endoderma do intestino posterior da membrana anal ectodérmica (BROWN et al., 2007).

Os animais acometidos morrem com cerca de sete a dezenove dias de idade, a menos que o defeito seja corrigido cirurgicamente. A ausência de fezes é acentuada. Quando o defeito é anal e o lúmen retal está quase contido no períneo, a intervenção cirúrgica é fácil e os resultados, em termos de salvação do animal para a produção de alimentos, são bons (RADOSTITS et al., 2002).

A presença de atresia anal, anomalias urogenitais e outras condições não letais associadas pode ocasionar doença debilitante, levar ao óbito em razão da 
interferência na fisiologia digestiva normal ou pode causar sérios problemas ao desenvolvimento normal do indivíduo (LOYNACHAN et al., 2006).

\section{PATOGENIA}

As anomalias anorretais derivam de defeitos da embriogênese do septo ano-retal. Embriologicamente, o canal e o reto se originam a partir de estruturas tubulares diferentes que devem unir-se fazendo desaparecer 0 septo que os divide (BOJRAB, 1981 apud TUDURY e LORENZONI, 1989). A imperfuração do ânus que ocorre na atresia anal pode ser devido a persistência da membrana anal, falha de união entre o reto e o canal anal ou aplasia do segmento terminal do reto (SLATTER, 1985 apud TUDURY e LORENZONI,1989).

\section{ACHADOS CLÍNICOS}

Radostits et al. (2002) relataram que animais acometido por atresia anal apresentarão abdômen visualmente distendido e aumento de volume na região perineal onde o ânus deveria estar. Em decorrência da distensão retal, há ausência de defecações, apatia, proeminência da pele da região perineal, falha de abertura do ânus e eliminação das fezes pela vulva (TUDURY e LORENZONI, 1989). Além disso, poderão apresentar disquezia, constipação, tenesmo associado à hipoquezia ou aquezia (TAGLIOLATTO JÚNIOR, 1989; MATTHIESEN e MARRETTA, 1998).

\section{DIAGNÓSTICO}

O diagnóstico se dá por meio do exame clínico, que é suficiente pela visualização da ausência da abertura anal, e os exames radiográficos não são essenciais, porém podem ser confirmatórios (RAHAL e MORTARI, 2007). 
À palpação abdominal, é possível observar a presença de cólon distendido e firme, impactado por fezes, sendo importante para avaliar a extensão e localização da estenose (MATTHIESEN e MARRETTA, 1998; DENOVO JÚNIOR e BRIGHT, 2004).

Em casos de atresia anal com fístulas reto-vaginal para se avaliar o tamanho e a localização da fístula deve ser realizado o exame de toque vaginal.

\section{TRATAMENTO}

O tratamento de uma estenose anal depende do grau de constrição anal, podendo ser clínico ou cirúrgico (HABR-GAMA et al., 1991). Em casos de constrições superficiais, que estão envolvendo somente a mucosa e a submucosa, é possível realizar dilatação com sondas, com o aumento do calibre, conforme a nova cicatrização vai ocorrendo. Nestes casos, está indicada a administração de corticosteróides durante três semanas após o procedimento (MATTHIESEN e MARRETTA, 1998; THOMAS et al., 2001).

Em casos cirúrgicos para correção da imperfuração anal e da fístula retovaginal, Slatter (1985) aconselhou incisar a fístula, suturando o teto da vagina, tracionar o reto e suturar sua parede a do canal anal.

Moya et al. (2008) ao descreverem um caso clínico de atresia anal associado a uma fístula reto-vaginal, optaram pelo tratamento cirúrgico, devido ao tipo de atresia diagnosticada do tipo I. Nos procedimentos préanestésicos foi realizada anestesia inalatória em combinação com anestesia epidural de cloridrato de lidocaína no espaço lombo-sacral. A cirurgia foi iniciada com uma episiotomia, a fim de localizar a fístula, suturar o espaço existente entre a vagina e o reto para eliminar o espaço morto, reconstituir o reto e por fim, delimitar a abertura anal.

No pós-cirúrgico, Moya et al.(2008) indicaram uma dieta balanceada e administração de antibióticos e antiinflamatórios. 
Segundo Niebauer (1996) a forma de tratamento é a correção cirúrgica, sendo que cada estágio da anormalidade exige um procedimento. Lesões do tipo IV requerem fechamento dos defeitos retais, vaginais e uretrais, sendo necessária uma abordagem abdominal para que a porção terminal do cólon e o reto sejam mobilizados.

A atresia anal se define pelo não desenvolvimento da abertura anal. Geralmente existe pouco mais que a pele e subcutâneo permanecendo imperfurada, e pode ser possível uma reconstrução cirúrgica satisfatória desde que o esfíncter muscular e o reto estejam adequadamente preservados (NIEBAUER, 1996).

\section{PROGNÓSTICO}

O prognóstico desta anomalia é reservado quando, devido à demora do proprietário em constatar o transtorno, desenvolve-se grave megacólon. Além disso, o índice de mortalidade trans-operatório desses pacientes é alto (SLATTER, 1985).

\section{PREVENÇÃo e CONTROLE}

Alguns autores sugerem que a doença apresentea hereditariedade (RADOSTITS et al., 2002). Assim, a utilização destes animais para a atividade reprodutiva deve ser descartada, a fim de evitar a propagação desta malformação congênita.

\section{CONSIDERAÇÕES FINAIS}

A atresia anal associada à fístula reto-vaginal é de ocorrência esporádica, mas ainda assim preocupa diante de seu caráter hereditário, exigindo então um manejo mais adequado quando da utilização de matrizes com histórico da anomalia. Com vista na associação destas malformações, preconiza-se um 
rápido diagnóstico e acompanhamento adequado, a fim de reduzir a morbimortalidade nos primeiros dias de vida.

\section{REFERÊNCIAS}

ARCHIBALD, J. Canine surgery. $2^{\text {a }}$ ed. 1974. 1172p.

ARONSON, L. Rectum and anus. In: SLATTER, D. Textbook of small animal surgery. Philadelphia: Saunders. Cap.43, p.167-180, 2002.

BARBOSA, R.D. Estenose anal em bezerro e abscessos múltiplos intermusculares, possíveis de correlações. Teresina, PI. Originalmente apresentada como defesa do Estágio Curricular Supervisionado Obrigatório II, Universidade Federal do Piauí, 1983.

BERG, R. Anatomia topográfica y aplicada de los animales domésticos. Madrid, Editorial AC, 1978, 415p.

BROWN, C.C. et al. Alimentary system. In: JUBB, K.V.F. et al. Pathology of domestic animals. San Diego: Academic. v.2, cap.1, p.3-296, 2007.

CAMPOS, K.F. et al. Doenças congênitas em bovinos diagnosticadas pela central de diagnóstico veterinário (cedivet) da Universidade Federal do Pará, no período de 1999 a 2009. Ciência Animal Brasileira - Suplemento 1, 2009 - Anais do VIII Congresso Brasileiro de Buiatria.

CAPELLA, MR; COLS. Incidência de malformações genitourinárias em crianças com anomalias anorretais. J Pediatr (Rio Janeiro), v.66, p.77-82, 1990.

CHO, D.Y.; TAYLOR, H.W. Cornell Veterinary, v.76, p.11, 1986.

DELLMANN, H.D.; BROWN, E.M. Histologia Veterinária. Rio de Janeiro, Guanabara Koogan, 1982.

DENOVO, R.C.; BRIGHT, R.M. Doença retoanal, p.1325-1339. In: Ettinger S.J. \& Feldman E.C. (Eds) Tratado de Medicina Interna Veterinária: Doenças do cão e do gato. 5 . ed. Guanabara Koogan, Rio de Janeiro, 2004. 2156p.

DE VREIS, P.A; COX, K.L. Surgery of anorectal anomalies. The Surgical Clinics of North America, v.65, p.1139-1169, 1985.

DYCE, J.M., SACK, W.O., WENSING, C.I.G. Tratado de Anatomia Veterinária. Rio de Janeiro: Guanabara Koogan, 1990.

FELIPE, A. E. Introducción a la teratología: el estudio de las malformaciones congénitas em medicina veterinaria. Revista Electrónica de Veterinaria, España, v. 4, n. 4, 2003.

Disponível em: http://www.veterinaria.org/revistas/redvet/n040403.html Acesso em 23 abr.2011.

GERALDO NETO, S. A. et al. Abortos e malformações em caprinos associados à ingestão de Aspidosperma pyricollum (Aponaceae). In: CONGRESSO BRASILEIRO DE BUIATRIA, 4, 2001, Campo Grande. Anais... Campo Grande: Editora Oeste, p. 184, 2001. 
GOMES, V. Atresia anal em bezerro: relato de caso. Revista Científica Eletrônica de Medicina Veterinária. Ed $2^{\circ}$ - Janeiro, 2004.

HABR-GAMA, A.; ALVES, P. R. A.; RODRIGUES, L. V.; VIEIRA, M. J. F. Anoplastia para Tratamento da Estenose Anal. Revista Brasileira de Coloproctologia, v. 11, n. 1, p. 15-18, 1991.

KIESEWETTER, S.B. Tectum and anus - malformations. In: Ravitch MM, Welsch MR, Benson CD, Aberdeen E, Randolph JG, ed. Year Book Medical Publishers, v. 98, p.1059-1072, 1979.

KÖNIG, H.E.; LIEBICH, H.G. Anatomia dos Animais Domésticos: Texto e atlas colorido. Porto Alegre: Artmed, 2002.

LOYNACHAN, A.T. et al. Complete diphallia, imperforate ani (type 2 atresia ani), and an accessory scrotum in a 5 -dayold calf. Journal of Veterinary Diagnostic Investigation, Columbia, v.18, n.4, p.408-412, 2006.

Disponível em: <http://jvdi.org/cgi/reprint/18/4/408.pdf>. Acesso em: 23 abr. 2011.

MATTHIESEN, D.T.; MARRETA, S.M. Afecções do ânus e reto. In: SLATTER, D. Manual de cirurgia de pequenos animais. 2.ed. São Paulo: Manole, v.2, cap.46, p.760-780, 1998.

MEDEIROS, J.M.; TABOSA, I.M.; SIMÕES, S.V.D.; NÓBREGA JÚNIOR, J.E.; VASCONCELOS, J.S.; RIET-CORREA, F. Mortalidade perinatal em caprinos no semi-árido da Paraíba. Pesquisa Veterinária Brasileira, v.25, n.4, p.201-206, 2005.

MORAES, R.V. Anomalias anorretais. In: Viegas D, Moraes RV, ed. Neonatologia Clínica e Cirúrgica. São Paulo: Livraria Atheneu, vol. 2, p. 1005-1022, 1986.

MOYA, L.E.G. et al. Resolución quirúrgica de una atresia anal associada a fístula rectovaginal en un cachorro. Revista veterinária, v.19, n. 1, p. 46-49, 2008.

NIEBAUER, G.W. Moléstia Retoanal. In: BOJRAB, M.J. Mecanismos da moléstia na cirurgia dos pequenos animais. 2. ed. São Paulo: Manole, cap. 48, p.323-338, 1996.

NIEBERLE, K.; COHRS, P. Anatomia patológica especial dos animais domésticos. $5^{\circ} \mathrm{Ed}$. Lisboa, Calouste Gulbenkian, v.1, 1970. 721p.

PENÃ A. Tratamento atual das anomalias anorretais. Clínica Cirúrgica da América do Norte, p.1431-1457, 1992.

PIMENTEL, L. A. et al. Mimosa tenuiflora as a cause of malformations in ruminants in the Northeastern Brazilian semiarid rangelands. Veterinary Pathology, Washington, v. 44, n. 6, p. 928-931, 2007.

PUGH, D. G. Clínica de ovinos e caprinos. São Paulo: Ed. Roca, 2004. 513p.

RIET-CORReA, F.; Medeiros, R.M.T.; DANTAS, A.F.M. Plantas Tóxicas da Paraíba. Centro de Saúde e Tecnologia Rural. Sebrae/PB, João Pessoa, PB. 2006. 58p.

RADOSTITS, O.M.; GAY, C.C.; BLOOD, D.C.; HINCHCLIFF, K.W. Clínica Veterinária: Um tratado de doenças dos bovinos, ovinos, suínos, caprinos e eqüinos. 9a ed. Rio de Janeiro: Guanabara Koogan S. A., 2002. 1737p.

RAHAL, S. C.; VICENTE, C. S.; MORTARI, A. C.; MAMPRIM, M. J.; CAPORALLI, E. H. G. Rectovaginal fistula with anal atresia in 5 dogs. Canadian Veterinary Medical Association, p. 827-830, 2007. 
REBHUN ,W.C. Doenças do gado leiteiro. 1 ed. São Paulo:Roca, p. 179-180, 2000.

ROTTA, I.T.; TORRES, M. B. A. M.; MOTTA, R. G. Diprosopia em bovino [Bovine diprosopus]. Arquivo Brasileiro de Medicina Veterinária e Zootecnia, Belo Horizonte, v. 60, n. 2, p. 489-491, 2008.

SANTOS ,J.A. Patologia Especial dos Animais Domésticos (Mamíferos e Aves). 2 ed. Instituto Interamericano de Ciências Agrícolas da OAE. 1975.

SANTOS, M. S. et al. Diprosopo em bezerro (relato de caso). Revista Brasileira de Saúde e Produção Animal, Salvador, v. 6, n. 1, p. 24-30, 2005.

SCHILD, A. L. et al. Arthrogriposis in Murrah buffaloes in southern Brazil. Pesquisa Veterinária Brasileira, Rio de Janeiro, v. 23, n. 1, p. 13-16, 2003.

SCHMIDT, V.; OLIVEIRA, R. T. Artrogripose em caprino: Relato de caso. Arquivo Brasileiro de Medicina Veterinária e Zootecnia, Belo Horizonte, v. 56, n. 4, p. 38-440, 2004.

SCHWARZE, E. Sistema visceral. In: Compêndio de Anatomia Veterinária. Zaragoza, Acribia, 1971.

SIEGMUND, O.H.; FRASER, C.M.; ARCHILBALD, J.; BLOOD, D.B.; HENDERSON, J.A.; NEWBERNE, P.M.; SNOEYENBOS, G.H.; WIPERS, S. W. C. El manual merck de veterinária. 2 ed. Rahway, Merck, 1981. 1.386p.

SISSON, GROSSMAN. Anatomia dos animais domésticos. 5. ed. Rio de Janeiro: Guanabara Koogan, v. 1., p. $848-851,1986$.

SLATTER, D.H. Textbook of small animal surgery. v.1, 1985. 1485 p.

TAGLIOLATTO Jr L. Estenose anal cicatricial: anoplastia por deslizamento de duplo retalho. Revista Brasileira de Coloproctologia, v.9, p.146-150, 1989.

THOMAS, D.A.; SIMPSON, J.W.; HALL, E.J. "Enfermedades del intestine grueso". Manual de Gastroenterologia en pequenos animals, 2001.

TUDURY, E. A.; LORENZONI, O.D. Colostomia em uma gatinha com atresia anal e fístula retovaginal. Revista do Centro de Ciências Rurais, Santa Maria, v.19, n.1-2, p.155-162,1989.

VIANNA, M.L.; TOBIAS; K.M. Atresia Ani in the Dog: A Retrospective Study. Journal of the American Animal Hospital Association, v.41, p.317-322, 2005. 